\title{
A ARITMÉTICA DO CURSO PRIMÁRIO PARAENSE E O MANUAL DIDÁTICO DO AUTOR CEZAR PINHEIRO DE 1902
}

\section{THE ARITHMETIC OF THE PARAENSE PRIMARY COURSE AND THE DIDACTIC MANUAL OF THE AUTHOR CEZAR PINHEIRO OF 1902}

\author{
Ana Paula Nascimento Pegado Couto ${ }^{1}$ \\ Universidade do Estado do Pará
}

\section{Resumo}

Este trabalho é um recorte do Trabalho de Conclusão de Curso de Licenciatura em Matemática defendido em 2017, que teve por objetivo investigar os saberes elementares de Aritmética que circularam em manuais escolares e programas de ensino na cidade de Belém, no Estado do Pará, no período de 1900 a 1910. A investigação tomou como fontes privilegiadas os programas de ensino da época e de que forma eles influenciaram os manuais escolares de Aritmética do período em questão. Dentre os manuais analisados, apresentamos neste artigo a análise do manual intitulado "Arithmetica Primaria" do autor Cezar Pinheiro, datado de 1902. A análise norteou-se pelos seguintes critérios: os aspectos físicos do manual e a abordagem dos conteúdos, além de verificar se o mesmo está de acordo com o Programa de ensino do período em questão. Nesta perspectiva, adotamos as 4 funções desenvolvidas por Choppin (2000) como elementos de categorização e análise. Como fundamentação teórica e metodológica utilizamos os estudos que discorrem sobre a história de uma disciplina, assim como sobre os manuais escolares e sobre a cultura escolar. Neste sentido, adotamos os tipos de pesquisa bibliográfica e documental. Depreende-se da análise que o manual apresenta alguns dos requisitos propostos no Regulamento Geral do Ensino Primário de 1903, entre os requisitos estão: os conteúdos abordados e a proposta de um compendio resumido em suas definições. $\mathrm{Na}$ análise realizada, percebemos que o manual publicado no período republicano paraense, momento de grandes reformas no ensino, seguiu em partes as orientações do programa de ensino delimitado no período de 1900 a 1910, além de contribuir para a literatura parense como um manual de um autor da própria região.

Palavras-chave: História da Educação Matemática; Ensino primário; Saberes Elementares; Manuais Escolares; Aritmética.

\section{Abstract}

This work is a clipping of the Conclusion Work of a Degree in Mathematics defended in 2017, whose objective was to investigate the elementary knowledge of Arithmetic circulated in school textbooks and teaching programs in the city of Belém, in the State of Pará, in the period from 1900 to 1910. The research took as privileged sources the teaching programs of the time and in what form they influenced the school textbooks of Arithmetic of the period in question. Among the manuals analyzed, we present in this article the analysis of the manual titled "Arithmetica Primaria" by the author Cezar Pinheiro, dated 1902. The analysis was guided by the following criteria: the physical aspects of the handbook and the content approach, as well as verifying if it is in

\section{1 ana.couto16@hotmail.com}


accordance with the teaching program of the period in question. In this perspective, we adopt the four functions developed by Choppin (2000) as elements of categorization and analysis. As a theoretical and methodological basis we use studies that discuss the history of a discipline, as well as school textbooks and school culture. In this sense, we adopt the types of bibliographic and documentary research. It appears from the analysis that the manual presents some of the requirements proposed in the General Regulation of Primary Education of 1903, among the requirements are: the contents addressed and the proposal of a summary summarized in its definitions. In the analysis carried out, we noticed that the manual published in the Republican period, at the time of major reforms in teaching, followed in part the guidelines of the teaching program delimited in the period from 1900 to 1910 , besides contributing to Parense literature as a manual of one author of the region.

Keywords: History of Mathematics Education; Primary school; Elementary Knowledge; School Manuals; Arithmetic.

\section{Introdução}

Este estudo apresenta uma parte das pesquisas realizadas para a elaboração do Trabalho de Conclusão de Curso (TCC) intitulado "Os Saberes Elementares de Aritmética nos Manuais Escolares que circularam em Belém no período de 1900 a 1910" tendo como questão norteadora "Quais os saberes elementares de aritmética que circulavam nos manuais escolares e programas de ensino em Belém do Pará no período de 1900 a 1910?”.

Para o desenvolvimento desta pesquisa adotamos como metodologia a pesquisa histórico-documental-bibliográfica, pois analisamos fontes documentais, como os manuais escolares da época, programas de ensino, legislações e estudos que discorrem sobre o ensino primário no Pará, com o intuito de conhecer os saberes elementares de aritmética que circulavam na referida época.

Estudos sobre os saberes elementares matemáticos no ensino primário vêm despertando, nas últimas décadas, o interesse de pesquisadores por todo o Brasil. Segundo André Chervel (1990) estudar historicamente os conteúdos que fazem parte do ensino primário ou secundário raramente despertou o interesse tanto de pesquisadores quanto do público. No entanto, mais recentemente, tem se manifestado uma tendência em favor de uma história de sua própria disciplina, dos conteúdos, tais como são dados nos programas de ensino. Os saberes elementares matemáticos destinados ao ensino primário brasileiro se constituem em três áreas de conhecimento, a Aritmética, a 
Geometria e o Desenho. E neste trabalho, daremos enfoque aos saberes elementares de Aritmética em Belém no período de 1900 a 1910.

O trabalho de conclusão de curso constitui a análise de três manuais escolares, e neste artigo apresentaremos a analise de um dos manuais que o contemplam. Neste sentido, este artigo tem como objetivo investigar os saberes elementares em Aritmética presente na $2^{\text {a }}$ edição da obra de Cezar Pinheiro publicada em 1902.

\section{Fundamentação Teórica e Metodológica}

Neste caminho trilhado, tendo como fontes de pesquisa os manuais escolares e programas de ensino, entende-se que o pesquisador está buscando conhecer e compreender os fenômenos sociais e culturais que predominaram em uma determinada época, considerando que estes fatores influenciam diretamente na organização do sistema de ensino. Fundamentados nesta perspectiva faremos uso do aporte teórico da história do livro e das edições didáticas desenvolvidas por Choppin (2004), privilegiando como via de estudo as análises dos conteúdos ensinados pela investigação dos manuais didáticos de Aritmética.

Em relação à análise dos manuais escolares, cabe ao historiador, sobretudo, considerar que "todo manual didático está histórica e geograficamente determinado e é produto de um grupo social e de uma dada época" (CHOPPIN, 2000, p. 116). Assim, a análise dos manuais escolares pode proporcionar identificar os traços culturais de um determinado contexto histórico em uma dada região, bem como identificar a organização dos conteúdos e programas de ensino de uma determinada época, além de possibilitar a identificação dos elementos construtores das metodologias de ensino empregadas pelos professores.

Entretanto, realizar essa análise é uma tarefa complexa, pois requer de o pesquisador definir os objetivos traçados de acordo com o material encontrado. Segundo Choppin (2004) a complexidade reside no fato de o manual assumir múltiplas funções das quais nós, enquanto pesquisadores, selecionamos as que mais se identificam com os nossos objetivos.

De acordo com este autor, o estudo histórico mostra que os manuais escolares exercem 4 funções essenciais, a saber: Função referencial, também chamada de curricular ou programática, nesta o livro didático é então apenas a fiel tradução do 
programa ou uma de suas possíveis interpretações; a Função instrumental, o livro didático põe em prática métodos de aprendizagem, propõe exercícios e atividades que visam a facilitar a memorização dos conhecimentos, a apropriação de habilidades, de métodos de análise ou de resolução de problema; Função ideológica ou cultural, nesta o livro didático se afirmou como um dos vetores essenciais da língua, da cultura e dos valores das classes dirigentes, assumindo um importante papel político; e por último a Função documental, na qual acredita-se que o livro didático pode fornecer um conjunto de documentos, textuais ou icônicos, cuja observação ou confrontação podem vir a desenvolver o espirito crítico do aluno. (CHOPPIN, 2004, p. 553)

Essas funções podem variar consideravelmente segundo o ambiente sociocultural, à época, as disciplinas, os níveis de ensino, os métodos e as fórmulas de utilização, assim, a pesquisa histórica sobre os livros e edições didáticas aborda aspectos extremamente diversos. Nesta pesquisa tomaremos as 4 funções desenvolvidas por Choppin como elementos de categorização e análise. Além de adotar duas categorias de análise, a saber: Materialidade do Manual e Abordagem dos conteúdos.

$\mathrm{Na}$ primeira categoria, compreendemos por materialidade os aspectos físicos do manual, como: estrutura e apresentação da capa; etapa de ensino ao qual se destinava; edição, paginação, quantidade de capítulos ou seções, informações sobre o autor e orientações apresentadas pelo mesmo. Nesta segunda categoria levamos em consideração a organização do conteúdo no manual, como: a linguagem utilizada para abordar os conteúdos matemáticos, se há ilustrações ou não; como são apresentados os exemplos; tipos de exercícios e problemas propostos. Além de verificar se os manuais escolares estão condizendo com a legislação vigente e os Programas de ensino do período analisado.

\section{Analise do Manual}

O manual analisado é intitulado Arithmetica Primaria do autor Cezar Pinheiro, em sua $2^{a}$ edição, publicado em 1902, pela Livraria Moderna, aprovado e mandado adaptar pelo Conselho Superior da Instrução Pública do Estado do Pará.

Em relação aos aspectos físicos do manual, a capa não apresenta ilustrações e nem cores. É uma capa simples com poucos elementos visuais. Ainda na capa é destacada que este exemplar, assim como o da $1^{\mathrm{a}}$ edição, foi aprovado e adaptado pelo 
Conselho Superior da Instrução Pública do Estado do Pará tendo como autor o professor Normalista Cezar Pinheiro, natural da cidade de Bragança no Estado do Pará, foi aluno da Escola Normal. Em 1886 foi deputado pelo $4^{\circ}$ distrito da Província do Pará e foi o primeiro diretor do Grupo Escolar José Veríssimo.

O manual apresenta capa, contracapa e folha de rosto. A primeira parte refere-se a uma apresentação do manual do próprio autor. A segunda parte apresenta a documentação de sua adoção e aprovação pelo Conselho Superior da Instrução Pública do estado do Pará. A terceira parte apresenta os assuntos propriamente ditos sobre o conteúdo matemático.

Nas primeiras páginas deste livro encontramos uma mensagem inicial intitulada "Ao leitor" que supomos que seja destinada aos professores, pois se refere a "nobre classe do professorado".

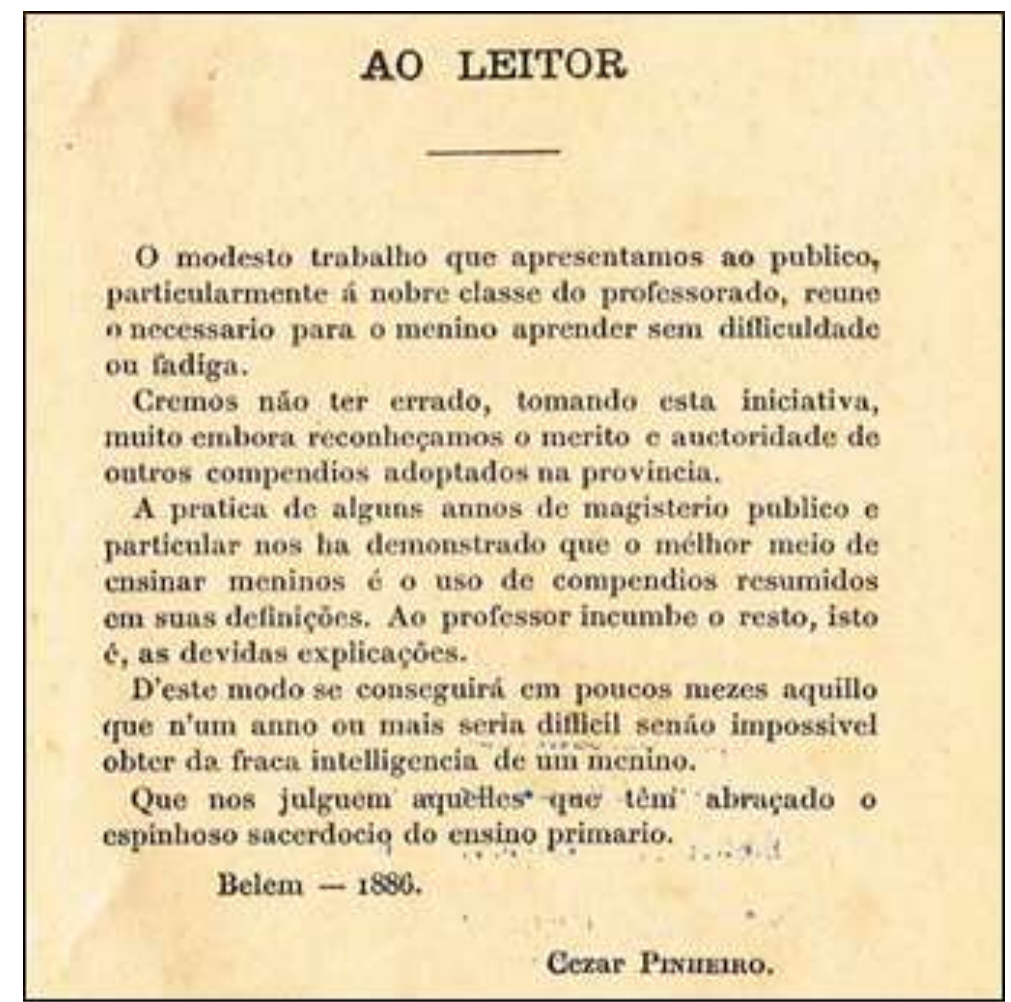

Figura 1: Mensagem inicial do manual Arithmetica Primaria Fonte: Pinheiro (1902, p. 4)

Na nota o autor relata que o exemplar reúne o necessário para o menino aprender sem dificuldade ou fadiga, justificando que o melhor meio de ensinar meninos é o uso de compêndios resumidos em suas definições, assim, incube ao professor o resto, isto é, 
as devidas explicações. Desta forma, o autor apresenta o critério adotado para a abordagem dos conteúdos, no qual enfatizado as Definições com o objetivo de conseguir em poucos meses aquilo que um ano ou mais seria difícil ou impossível. (PINHEIRO, 1902, p. 4)

Nesta obra não encontramos sumário que apresentassem o conteúdo trabalhado, então sintetizamos alguns dos conteúdos abordados pelo livro para facilitar o manuseio do mesmo. Como mostra o quadro 1.

Quadro 1 - Conteúdo do livro Arithmética Primaria - Cezar Pinheiro, 1902

\begin{tabular}{|c|c|c|}
\hline TÓPICOS & CONTEÚDO & PÁGINAS \\
\hline I & Numeração & 8 \\
\hline II & Operações Fundamentaes & 11 \\
\hline III & Fracções & 23 \\
\hline IV & Systema Metrico Decimal & 37 \\
\hline V & Números Complexos & 48 \\
\hline VI & Proporções & 55 \\
\hline VII & Regra de Três & 57 \\
\hline VIII & Regra de companhia & 61 \\
\hline IX & Regra de Juros & 69 \\
\hline X & Progressões & 73 \\
\hline
\end{tabular}

Fonte: Elaborado pela autora

Antes de iniciar o tópico I - Numeração, o autor inicia com uma consideração inicial, intitulada Introducção, a respeito da Aritmética e algumas definições preliminares do conceito de quantidade, unidade e número. Nesta introdução o autor define a Aritmética como a sciencia de contar, ou seja, o conhecimento que envolve a contagem por meio de números. O manual é composto por 78 páginas e conseguimos identificar 10 conteúdos contidos na obra.

No que se refere à organização didática dos conteúdos, o autor ao iniciar cada tópico segue a mesma estrutura: Definição; Regra (algoritmo na forma escrita); e Exemplo. Não se observa no livro a presença de Exercícios de qualquer origem. Para exemplificar essa organização didática escolhemos o conteúdo de Operações Fundamentais, especificamente a operação de Adição.

Ao iniciar o tópico intitulado Operações Fundamentaes o autor faz uma pequena introdução sobre o que são essas operações, quantas e quais são elas. O autor ressalta que além das operações fundamentais aritméticas: soma ou adição, subtração, 
multiplicação e divisão, os autores modernos da época consideram mais duas operações: potenciação e radiciação, ambas também são trabalhadas no decorrer do manual. Posteriormente a essa introdução, o autor apresenta as seis operações, iniciando pela Somma. Na definição da operação de Soma, temos que:

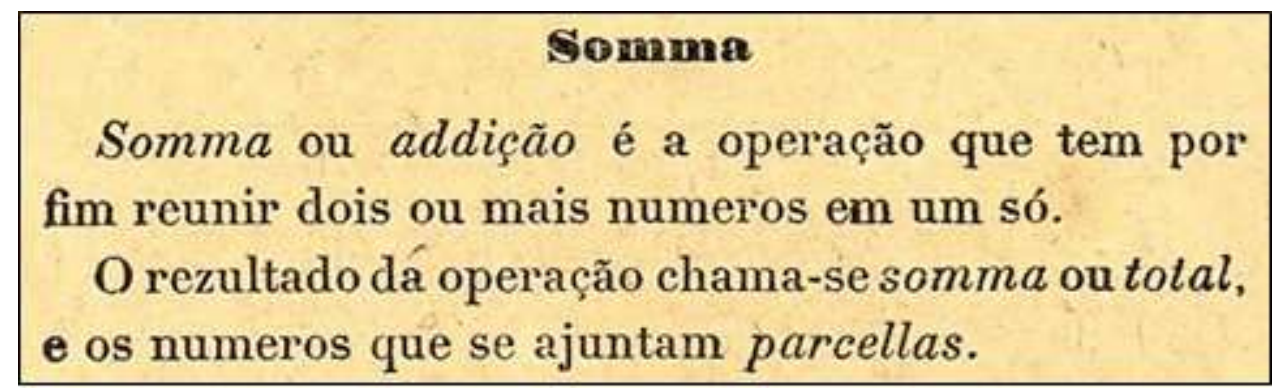

Figura 2: Definição da Operação de Soma

Fonte: Pinheiro (1902, p. 11)

Na figura 2, o ator define a operação de Soma como a reunião de dois ou mais números em um só e nomeia os termos da operação. Após a definição dada, o autor trás o algoritmo da soma em forma escrita, intitulada como Regra, ou seja, Regra da Soma.

REgRA. - Escrevem-se os algarismos uns por
baixo dos outros, ficando as unidades em uma
mesma columna vertical, as dezenas em outra,
bem como as centenas, etc.; depois traça-se por
baixo uma linha e sommam-se as columnas da di-
reita para a esquerda, juntando-se á columna se-
guinte as rezeroas da precedente, se houverem.

Figura 3: Regra da Operação de Soma Fonte: Pinheiro (1902, p. 11)

Nesta regra, usa-se o Sistema de numeração decimal (unidade, dezena e centena) para descrever o algoritmo da soma na forma escrita, ou seja, o passo a passo de como o aluno deve efetuar o cálculo desta operação. Neste sentindo, podemos inferir que esta estratégia de apresentar o algoritmo da forma escrita, seja para orientar o professor na sua explicação em sala de aula. Cabe ressaltar que o manual não apresenta nenhuma orientação didática ou pedagógica de qualquer origem. Logo após ser explicitada a regra 
do algoritmo da soma na forma escrita, o texto trás um exemplo com o algoritmo na forma numérica. Como mostra a figura 4 :

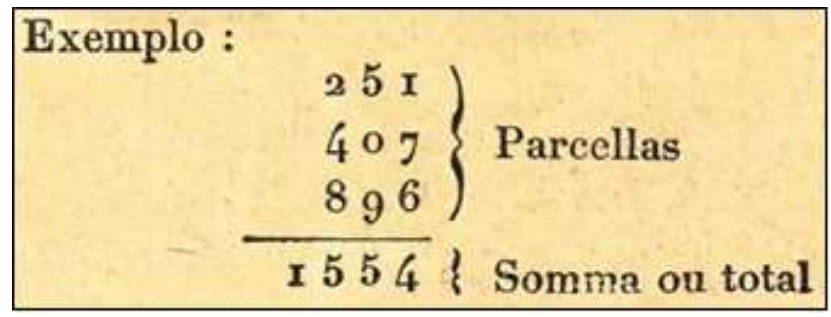

Figura 4: Exemplo da Operação de Soma

Fonte: Pinheiro (1902, p. 11)

$\mathrm{Na}$ figura 4, observa-se que o sinal da adição não aparece na estrutura tanto na Regra quanto no exemplo da soma, ele só é apresentado posteriormente com a soma dos algarismos na horizontal. Como mostra a figura 5:

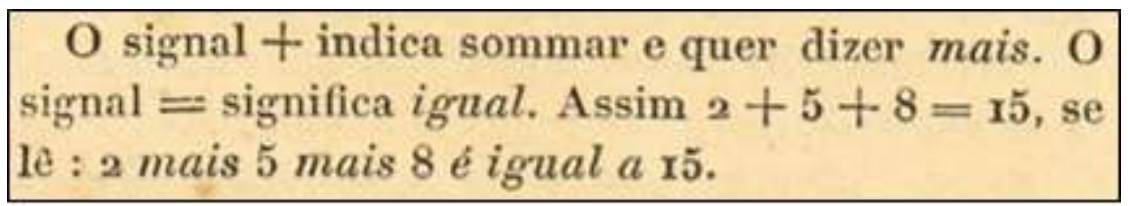

Figura 5: Sinal da Soma

Fonte: Pinheiro (1902, p. 12)

Em seguida apresenta dois modos de verificar se o resultado da soma está correto: a prova real e a prova dos noves fóra. Ambas apresentadas a seguir:

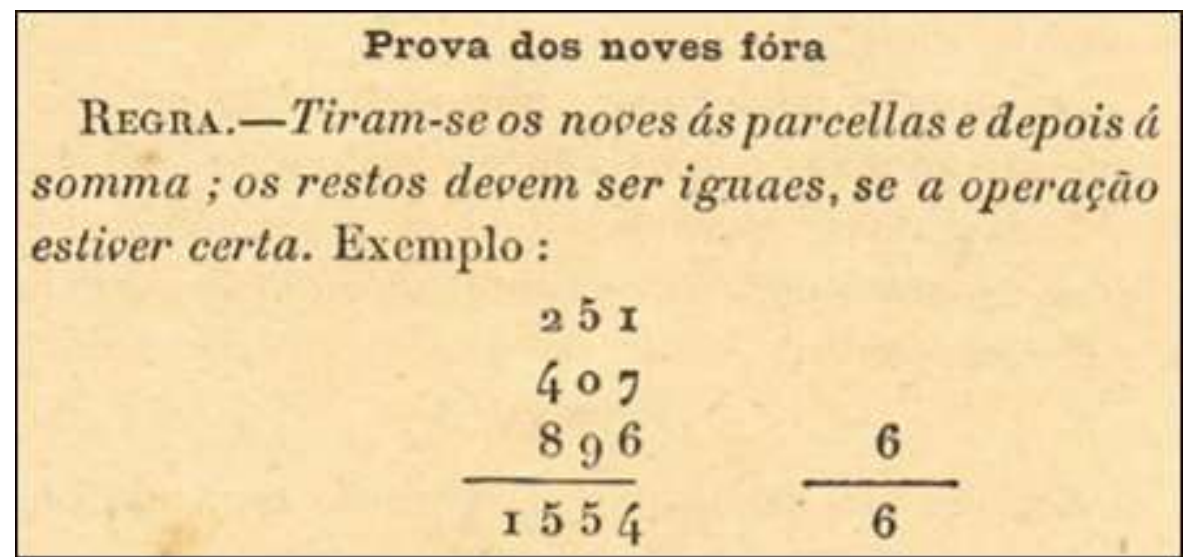

Figura 6: Prova dos noves fóra

Fonte: Pinheiro (1902, p. 12) 
A prova dos noves fora, apresentada na figura 6, consiste em verificar se o cálculo da soma está correta, a regra consiste em somar cada algarismo das parcelas com o seu respectivo sucessor, se essa soma passar de nove, tira-se nove, ou seja subtrai nove, no caso utiliza-se a expressão noves fóra, e assim sucessivamente até o último algarismo das parcelas. Da mesma maneira procede no Total. Saberemos se a operação está certa se o resto das parcelas for igual a do Total. No exemplo dado, temos que: $2+$ $5=7$, não passou de nove então continua somando, $7+1=8,8+4=12$, nesse caso passou de nove então fazemos os nove fóra $12-9=3$, e assim sucessivamente até o último algarismo das parcelas, $3+0=3,3+7=10,10-9=1,1+8=9,9-9=0,0+$ $9=9,9-9=0,0+6=6$. No total, temos que, $1+5=6,6+5=11,11-9=2,2+4=$ 6. Assim, o resultado das parcelas é 6, assim como o do total, desta forma a operação da soma está correta.

No entanto a prova dos noves pode levar a falsas verdades, ou seja, dá um resultado errado como certo. Podemos verificar essa incongruência em um exemplo bem simples, $234+167=401$, mas se por um acaso o aluno resolvesse de maneira equivocada, $234+167=210$ ou $234+167=392$, ambos os resultados estão errados, mas a prova dos noves fóra indicará como corretos. Esse é um dos motivos que a prova dos noves fóra não se usa mais como método para verificar se a operação da adição está correta.

Outra maneira apresentada no manual de se verificar se a operação de Adição está correta é a Prova Real:

Prova real da somma
REgra.-Somma-se de nooo a contar da esquerda
para a direita subtrahindo d'essa somma as novas
sommas das columnas correspondentes, não deven-
do ficar resto alsum se a operação for bem feita.

Figura 7: Prova real da soma

Fonte: Pinheiro (1902, p. 13)

A prova real indica a soma sucessiva da esquerda para a direita das diversas colunas, subtraindo a soma parcial de cada uma delas da soma total.

No exemplo da prova real na soma, temos que: a soma da $1^{\text {a }}$ coluna á esquerda dá 14 , que subtraído de 15 , restam 1 ; este resto, reunido ao algarismo seguinte 5 , forma 
14. A soma da $2^{\text {a }}$ coluna dá 14 , que subtraído de 15 , resta 1 ; este resto, reunido ao algarismo seguinte 4 , forma 14 . A soma da $3^{\text {a }}$ coluna dá 14 , que subtraído de 14 , resta 0 . Portanto a conta está certa. Este exemplo não é apresentado no manual, no entanto aplicamos a Regra da prova real na conta de adição exposta na figura 10 com o intuito de compreender o procedimento da prova real.

A prova real da soma exposta pelo autor na figura 7 , não expõem de maneira clara o procedimento a ser feito, assim como também ocorre na prova dos noves fóra na figura 6, ambas necessitaram de estudos além do manual para compreender os respectivos procedimentos. Diferentemente da prova real que conhecemos hoje que utiliza a operação inversa para verificar se os cálculos das operações estão corretos, no caso da adição, utiliza-se a subtração, na qual é necessário subtrair uma das parcelas do resultado da adição e obter a outra parcela como resultado.

As demais operações são detalhadas, passo a passo de acordo com as suas respectivas regras seguindo a mesma estruturação de exposição utilizada pela adição. $1^{\circ}$ a definição; $2^{\circ}$ a regra; $3^{\circ}$ o exemplo, que só é a aplicação da regra; $4^{\circ}$ a prova, a qual consiste em uma segunda operação, que fazemos para verificar se a primeira está correta; $5^{\circ}$ o uso, que indica em quais casos devemos empregar a operação (só observamos esses casos na operação de multiplicação e divisão).

A exposição dos demais conteúdos segue essa mesma organização didática. Assim, podemos identificar como o autor aborda os conteúdos no manual. Observou-se ainda na análise do manual que os conteúdos de cada capítulo são descritos sem ilustrações. Exceto o conteúdo de Systema Metrico Decimal que apresenta figuras com tamanhos consideráveis para representar as unidades de medidas que eles quantificam em seis unidades principais: Metro para as medidas de comprimento; Litro para as de capacidade; Gramma para as medidas de peso; Franco para moeda; Are medidas de superfície e Stere para as de volume. Entre essas, destacamos a medida de Stere por o autor ressalta que está unidade do sistema métrico não tem aplicação no Brasil, no qual é usado o metro cúbico. Portanto, além de ilustrar todas as unidades do sistema métrico por meio de figuras, o autor tem a preocupação de mostrar outras unidades sem ser as usuais no Brasil. 
Não se observa no manual Exercícios ou Problemas de qualquer origem, com exceção dos tópicos VIII e IX - Regra de Companhia e Regra de Juros - que exemplifica por meio de problemas práticos que já se encontram resolvidos.

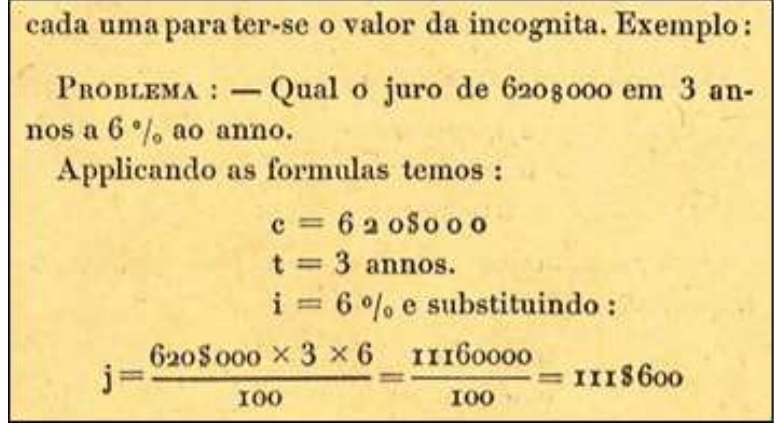

Figura 8: Problema da Regra de Juros Fonte: Pinheiro (1902, p. 71)

Na figura 8, o problema exposto é do conteúdo de Juros contido no tópico IX do manual. Cabe ressaltar que foi a primeira vez que o termo problema aparece na obra.

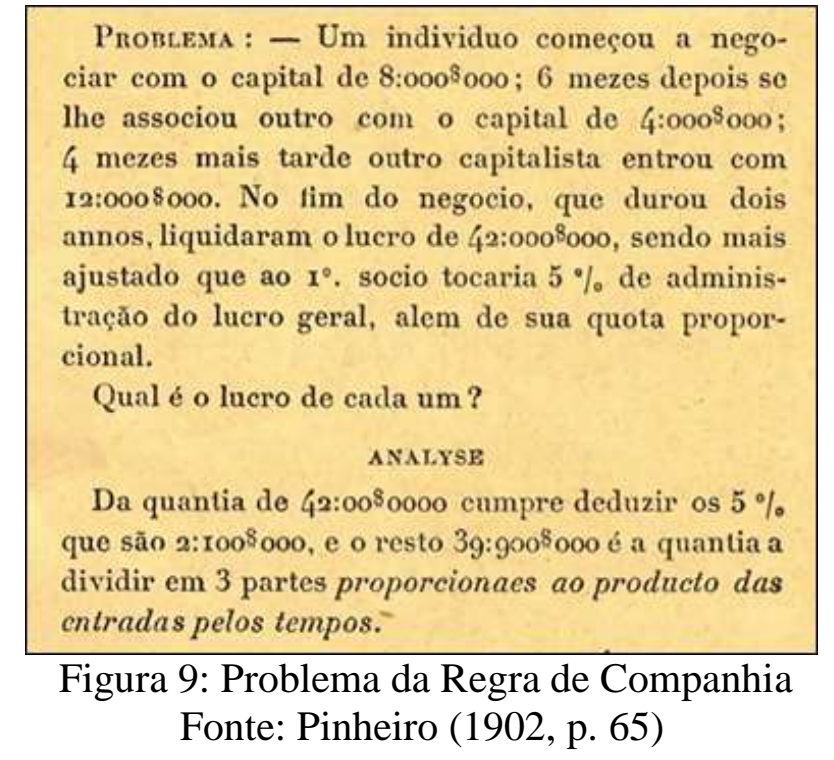

Pelos exemplos apresentados a partir do tópico de Regra de Companhia, inferese uma linguagem mais intuitiva, de exemplos envolvendo problemas com assuntos práticos do dia a dia, geralmente envolvendo questões financeiras como investimento de uma determinada quantia.

Na análise do manual podemos observar que não só os elementos de definição, mas a forma como o autor apresenta seus conteúdos permite aferir as concepções do 
formato da disciplina, que se constitui como um verdadeiro manual para o professor. Apreendesse que o autor dirige sua comunicação para o professor de primeiras letras e expõem a forma como tais conteúdos devem ser apresentados e desenvolvidos junto aos alunos.

O manual de Cezar Pinheiro abrange os conteúdos encontrados no programa curricular vigente aprovado no Regulamento Geral do Ensino Primário de 1903 para o ensino de Aritmética. Neste regulamento, o ensino primário divide-se em elementar e complementar, o elementar vai do primeiro ao quarto ano e o suplementar do primeiro ao segundo ano. Contudo há ausência no manual os estudos de divisibilidade, máximo comum e mínimo comum, noções elementares de números primos, que eram conteúdos relacionados ao terceiro ano do curso elementar.

Além dos conteúdos, no que se refere a proposta de ensino, o manual em seus texto preliminares ressalta que o exemplar reúne o necessário para o menino aprender sem dificuldade ou fadiga, justificando que o mélhor meio de ensinar meninos é o uso de compendios resumidos em suas definições, assim, incube ao professor o resto, isto é, as devidas explicações, essa abordagem é apresenta também nas observações do Programa de Ensino de 1903 no qual orienta o professor que para evitar a fadiga e a confusão do aluno deve-se aproveitar as matérias de mais utilidade do programa por meio de compendios resumidos e claros em suas definições.

Neste sentido, entendemos que o manual Arithmetica Primaria do autor Cezar Pinheiro, por mais que seja publicado um ano antes do programa de ensino de comparação, apresenta alguns dos requisitos propostos no Regulamento Geral do Ensino Primário de 1903. Como os conteúdos abordados e a proposta de um compendio resumido em suas definições.

$\mathrm{Na}$ análise realizada, percebemos que o manual publicado no período republicano paraense, momento de grandes reformas no ensino, procuram adaptar seus manuais aos programas de ensino da época. Os autores desta fase, de alguma forma contribuíram no ensino primário adaptando seus manuais aos programas de ensino delimitado no período em análise. Essa proposta é uma das funções que o manual escolar pode assumir de acordo com os estudos de Alain Choppin (2004).

De acordo com este autor, o estudo histórico mostra que os manuais escolares assumem múltiplas funções que podem variar consideravelmente segundo o ambiente 
sociocultural a época. (CHOPPIN, 2004, p. 553). Entre estas funções destacamos a Função Referencial, também chamada de curricular ou programática, na qual o manual é então apenas a fiel tradução do programa ou uma de suas possíveis interpretações, ele constitui o suporte privilegiado dos conteúdos educativos referentes ao programa de ensino vigente na época. Assim, podemos estabelecer esta função ao manual analisado nesta pesquisa, pois foi adaptados de acordo com os conteúdos do Programa de Ensino de 1903.

Além da função referencial, o estudo de Choppin (2004) ressalta que os manuais exercem mais três funções essências. A Função Instrumental, na qual o manual põe em prática métodos de aprendizagem, propõe exercícios ou atividades que, segundo o contexto, visam a facilitar a memorização dos conhecimentos, favorecer a aquisição de competências disciplinares ou transversais. Esta função não é apresentada pelo manual, pois não há notas explicativas, nem exercícios propostos como verificamos na análise, e apresentam apenas um exemplo de cada tópico abordado.

Outra função estabelecida por Choppin (2004, p. 553) é a Função ideológica e cultural, na qual o manual assume um importante papel político, um instrumento privilegiado de construção de identidade. Os manuais analisados foram publicados nas primeiras décadas do período republicano, momento de grandes mudanças politicas, econômicas e principalmente no sistema educacional, o que influenciou diretamente nos manuais e nas propostas de ensino da época como foco de mudar o ensino escolar colonial e monárquico para o ensino que propagou os ideais advindos da republica.

Por último destacamos a Função documental, a qual acredita-se que o manual didático pode fornecer, sem que sua leitura seja dirigida, um conjunto de documentos, textuais ou icônicos. Nesta pesquisa, os manuais assumem a função documental, pois são usados como fontes de pesquisa histórica para compreender o sistema de ensino de uma determinada época. Além de ser um documento que poderá ser usado para pesquisas futuras.

\section{Conclusão}


Este estudo teve como objetivo investigar os saberes elementares em Aritmética presente na $2^{\mathrm{a}}$ edição da obra de Cezar Pinheiro publicada em 1902.

$\mathrm{Na}$ análise do manual, podemos perceber que o método de ensino utilizado pelo autor é de definições mais resumidas e sem exercícios, cabendo ao professor o resto, assim como a linguagem mais técnica por se tratar de um manual destinado a classe do professorado, e utiliza uma abordagem mais clara e resumida com definição, regra e um exemplo. Como também o mesmo está de acordo com a legislação vigente da época de acordo com o Programa de Ensino aprovado pelo Regulamento Geral do Ensino Primário de 1903.

Embora nenhuma referência explícita tenha sido feita ao método intuitivo nos manuais, a sequência como os saberes referentes às operações fundamentais são apresentados, evidencia estreitas relações com este método de ensino, uma vez que, realizando-se exercícios práticos para depois se estudar os sinais e as definições das operações, parte-se do concreto para o abstrato.

Entendemos que a pesquisa e a análise das produções didáticas são de grande relevância, pois possibilitam um novo olhar sobre a educação no período em estudo, contribuindo com novas discussões para campo da História da Educação no Pará, ainda nascente. Assim, este trabalho buscou contribuir para o desenvolvimento acerca da História do ensino de Matemática em Belém, especificamente da Aritmética no período, de 1900 a 1910.

\section{Referências}

CHERVEL, André. História das Disciplinas Escolares: reflexões sobre um campo de pesquisa. Teoria e Educação. 1990. p.177-229.

CHOPPIN, A. História dos livros e das edições didáticas: sobre o estado da arte. In: Educação e Pesquisa. v.30, n.3, set. /dez. São Paulo, 2004, p. 549-566.

COUTO, Ana Paula Nascimento Pegado. Os saberes elementares de Aritmética em Belém no período de 1900 a 1910. 2017. 68 f. Trabalho de Conclusão de Curso (Licenciatura em Matemática) - Universidade do Estado do Pará, Belém, 2017.

\section{PARÁ. Estado. Regulamento geral do ensino primário reorganizado pelo Decreto n.1190 de 17 de fevereiro de 1903. Belém: Typ. Diário Oficial, 1903. 55p.}

PINHEIRO, Cezar. Arithmetica primaria: aprovada e mandada adoptar pelo conselho superior da instrução publica do estado do Pará. Belém: Moderna, 1902. 78p. 